\title{
BRIEF INFORMATION ABOUT THE SPECIES STATUS OF UTRICULARIA CORNIGERA STUDNIČKA
}

\author{
Miloslav StUdnIČKa • Liberec Botanic Gardens • Purkyňova 630/1 • CZ-460 01 Liberec • Czech \\ Republic・botangarden@volny.cz
}

Keywords: Utricularia cornigera, hybrid, heterosis, apomixis

\begin{abstract}
The carnivorous plant Utricularia cornigera Studnička was described in 2009, but authorities of the International Carnivorous Plant Society published an opinion that it is not a true species, but only a natural hybrid of U. reniformis and U. nelumbifolia. The role of heterosis is discussed, because $U$. cornigera is much larger than both theoretical parents. Seedlings, the very characteristic feature of bladderworts (Utricularia), are different in all the bladderworts described, that is, in the named species and in artificial hybrids of $U$. nelumbifolia and $U$. reniformis. No support for the hypothesis supposing a hybrid origin of $U$. cornigera was found.
\end{abstract}

\section{Introduction}

Recently a hypothesis appeared that Utricularia cornigera Studnička could be a hybrid of U. nelumbifolia Gardn. $\times$ U. reniformis St.Hil. (Schlauer 2011; Fleischmann 2012). Consequentially, the new species was rejected from the Carnivorous Plant Database (Schlauer 2011). Nevertheless it was accepted in the International Plant Name Index (IPNI 2005). This article presents the results of new experiments with artificial crossings of both theoretical parents proposed by the authors.

The manner of germination and specifically the appearance of the seedlings are crucial phenomena in the life strategy of bladderworts. In the Utricularia species from the section Iperua there are two different ways of germination: either by floating seedlings (e.g. U. cornigera, U. nelumbifolia), or by terrestrial seedlings (e.g. U. geminiloba, U. nephrophylla, and the true U. reniformis).

The difference was described and pictured as a very important diacritical attribute of $U$. cornigera as compared with U. reniformis (Studnička 2009). As mentioned in the previous paper, U. reniformis does not have whorl-shaped seedlings and it cannot germinate in water, but $U$. cornigera germinates in water. The floating whorl-shaped seedlings of $U$. cornigera are rather similar to the also whorl-shaped seedlings of the Brazilian U. nelumbifolia and the Venezuelan U. humboldtii Schomb. These species can use phytotelmes within the leaf rosettes of certain host plants to germinate (Taylor 1989; Studnička 2011).

\section{Methods}

Cultivated plants were used for manual hybridization, which was carried out during July and August 2012 in Liberec Botanic Gardens. Specific identity of U. reniformis is granted by a previous study made using the same material (Studnička 2009). Specific identity of $U$. nelumbifolia is clear because the stoloniferous plants distributed in European botanic gardens are of natural origin. Numerous fresh seeds (the whole content of at least 2 full seed capsules of each species or hybrid) were put into water in a glass and cultivated in a greenhouse. The seeds of $U$. reniformis, which could not germinate in such conditions, were also placed on a wet soil mix of peat and dried Sphagnum moss 1:1 and were also cultivated in the greenhouse. Just the soil surface provides suitable conditions for U. reniformis to germinate. 
The seedlings of $U$. reniformis, $U$. nelumbifolia, $U$. nelumbifolia $\times U$. reniformis, and $U$. reniformis $\times U$. nelumbifolia were documented by photographs taken using a Pentax $35 \mathrm{~mm}$ macro lens. The floating hybrid seedlings were compared with the seedlings of $U$. cornigera formerly used to describe the species (Studnička 2009).

Possible heterosis was evaluated according to the maximal size of the leaf blades found. The bladderwort $U$. cornigera was measured in natural localities as well as in cultivated specimens, both giant (Studnička 2009). The species U. nelumbifolia found thanks to F. Rivadavia near Teresópolis in Serra dos Órgãos was much smaller than the specimens cultivated in Liberec Botanic Gardens, which is why I present a measurement of a cultivated plant here. The leaf of the flowering cultivated specimen of $U$. reniformis used in this research was also measured and compared with the largest leaf found in natural conditions ( $c f$. Studnička 2009).

Results
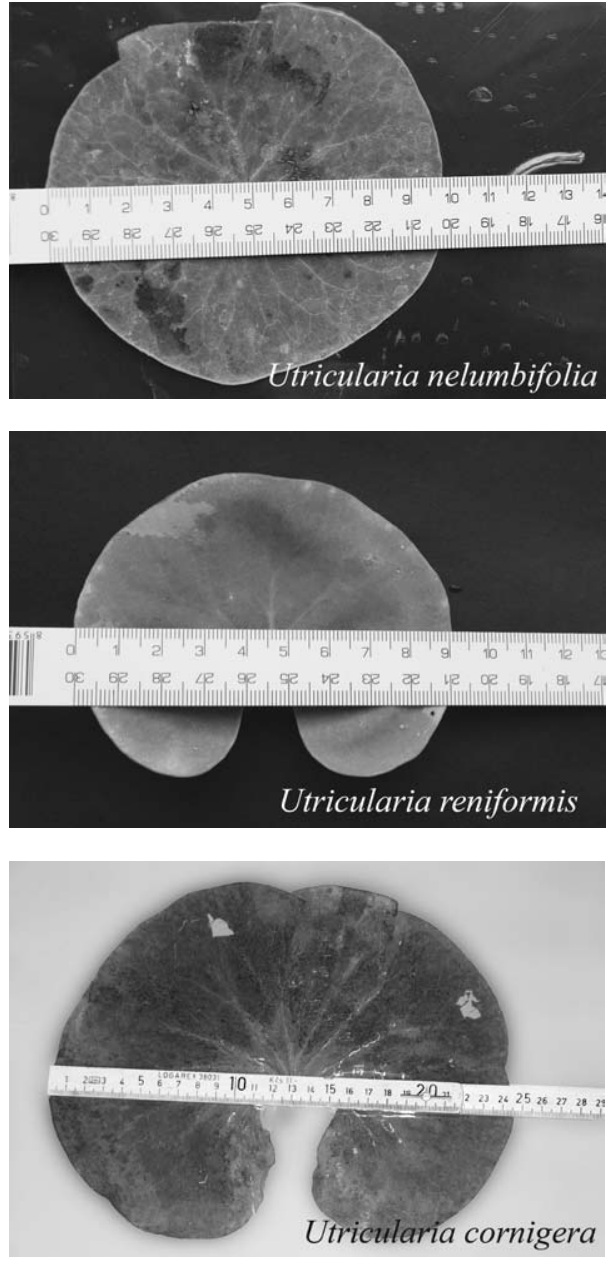

Figures 1-3: Leaves of luxurious specimens of cultivated bladderworts. The scale is in centimeters.
The question is whether the prospective hybrid theoretically resulting in U. cornigera would be an F1 generation or a descendant of multiple breeding. To assess this problem measurements of the largest known leaves in all three species in question are needed. I can give these dimensions: $U$ cornigera $24.4 \times 20.7 \mathrm{~cm}$ (cultivated specimen), but also up to $17.5 \times 13.0 \mathrm{~cm}$ in natural conditions; U. reniformis $9.2 \times 7.5 \mathrm{~cm}$ (cultivated specimen), but even $10.5 \times 8.5 \mathrm{~cm}$ in natural conditions; U. nelumbifolia $9.9 \times 9.6 \mathrm{~cm}$ (cultivated specimen), but distinctly smaller specimens were seen in natural conditions. The preserved leaf of $U$. cornigera photographed in this article is located in the PRC herbarium; the leaves of the other species are found in Liberec Botanic Gardens (www.botaniliberec.cz). It was documented that the leaf laminas of the theoretical parental species are both about half the size of those of $U$. cornige$r a$ (Fig. 1-3). If $U$. nelumbifolia and U. reniformis were the parents of $U$. cornigera, the giant size of its leaf lamina would be a sign of heterosis.

The seedlings of all three species are very characteristic. Are the juvenile hybrids of $U$. nelumbifolia $\times U$. reniformis (and conversely) similar to $U$. cornigera? The results of crossing experiments are documented below (Fig. 4-8).

\section{Discussion}

The bladderwort $U$. cornigera is much more vigorous than both $U$. nelumbifolia and U. reni- 

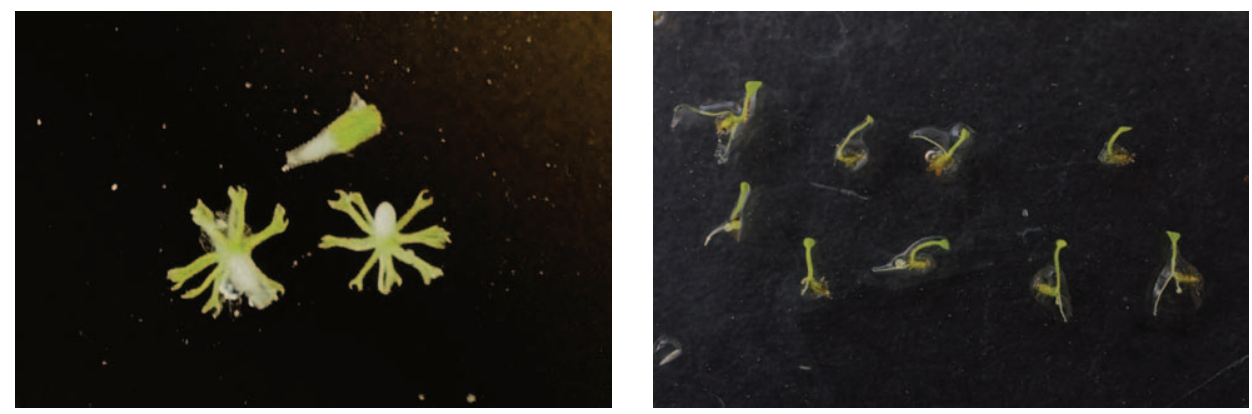

Figures 4-5: Floating seedlings of Utricularia nelumbifolia (left) and terrestrial seedlings of $U$. reniformis (right). These theoretical parents of $U$. cornigera were crossed artificially. (See the following figures.)
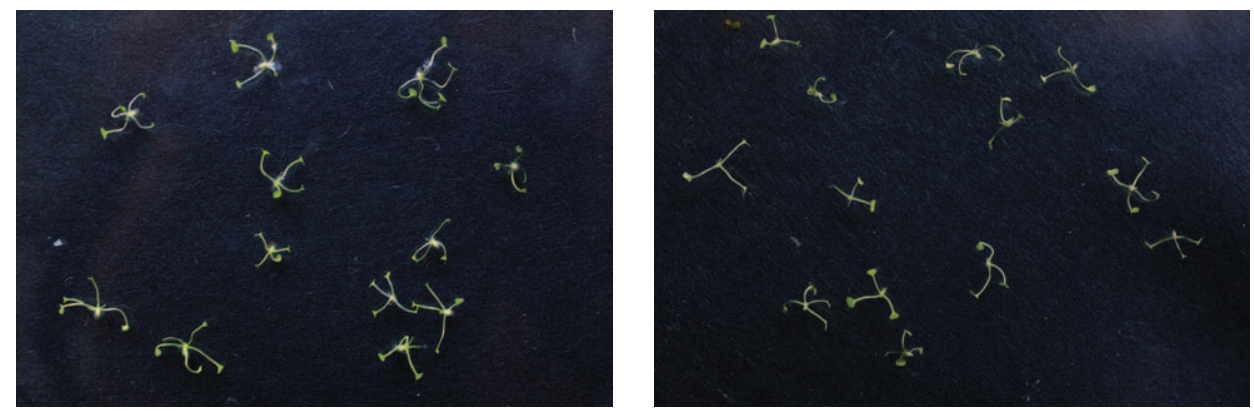

Figures 6-7: Seedlings of the hybrid Utricularia nelumbifolia $+\times U$. reniformis with 4-5 leaf primordia (left) and of the hybrid $U$. reniformis $+\times U$. nelumbifolia with 3-4 leaf primordia (right).

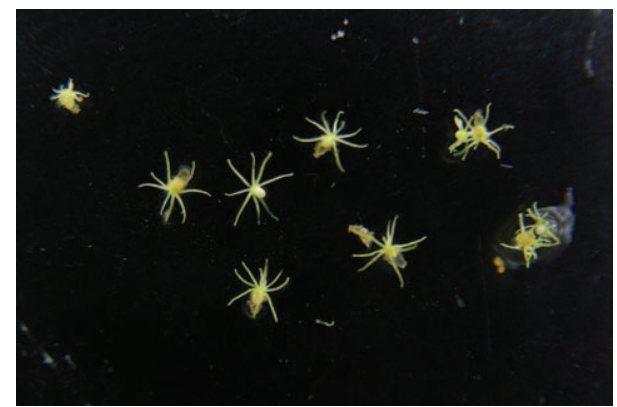

Figure 8: Seedlings of Utricularia cornigera with 6-8 leaf primordia are dissimilar to the hybrids pictured above.

formis. Therefore, the heterosis effect in the F1 crossbred generation should be noted, if U. cornigera were to be considered as a hybrid. The heterosis effect is, however, unsustainable in subsequent generations. The gigantism in U. cornigera (considered a hybrid) would be stable solely by two prerequisites: 1 . It is a primary hybrid; 2 . It propagates only asexually.

$U$. cornigera produces viable seeds, but they could theoretically be a result of apomixis. Nevertheless, research of seedlings made by crossbreeding experiments between $U$. nelumbifolia and $U$. reniformis indicates lower numbers of leaf

primordia in these hybrids in comparison with $U$. cornigera. This is clear evidence that the seedlings of $U$. cornigera cannot be an apomictic derivate of the hybrids $U$. nelumbifolia $\times U$. reniformis or $U$. reniformis $\times U$. nelumbifolia. Experience with a cultivated $U$. cornigera indicates that manual pollination is necessary to obtain seeds and seedlings. That is also a sign of normal sexual propagation. As the aforementioned prerequisites are not fulfilled, the idea that $U$. cornigera originated as a hybrid is not supported. According to this preliminary result, U. cornigera arose due to reproductive isolation, like other endemic plants restricted to the same area, rather than from a hybrid origin. The future study of 
traps, and or fertility/sterility in mature hybrids would also be interesting corroboration of the species status of U. cornigera.

\section{Conclusions}

1. The seedlings originating from both crossings of U. nelumbifolia and U. reniformis are dissimilar to seedlings of $U$. cornigera.

2. This fact excludes the possibility that $U$. cornigera could be an apomictic primary hybrid.

3. The bladderwort $U$. cornigera is the most vigorous species of the three named bladderworts, but no heterosis could survive in many generations of the sexually multiplying bladderwort. That is why it can hardly be a stabilized hybrid of much smaller parents.

Acknowledgement: I wish to thank Professor R. J. Válka Alves, University Federal do Rio de Janeiro, for his helpful suggestions.

\section{References}

Fleischmann, A. 2012. The new Utricularia species described since Peter Taylor's monograph. Carniv. Pl. Newslett. 41: 67-76.

IPNI. 2005. The International Plant Names Index. http://www.ipni.org/ipni/plantnamesearchpage.do, accessed 17 July 2012.

Schlauer, J. 2012. Carnivorous Plant Database. http://www.omnisterra.com/bot/cp_home.cgi, accessed 17 July 2012.

Studnička, M. 2009. Brazilian bladderwort Utricularia reniformis is a blend of two species. Thaiszia - J. Bot. 19: 131-143.

Studnička, M. 2011. Surprising phenomena in the life strategy of Utricularia reniformis in Brazil. Thaiszia - J. Bot. 21: 37-43.

Taylor, P. 1989. The genus Utricularia - a taxonomic monograph. Kew Bull. Additional Ser. XIV, Royal Bot. Gardens, Kew. 723 p.

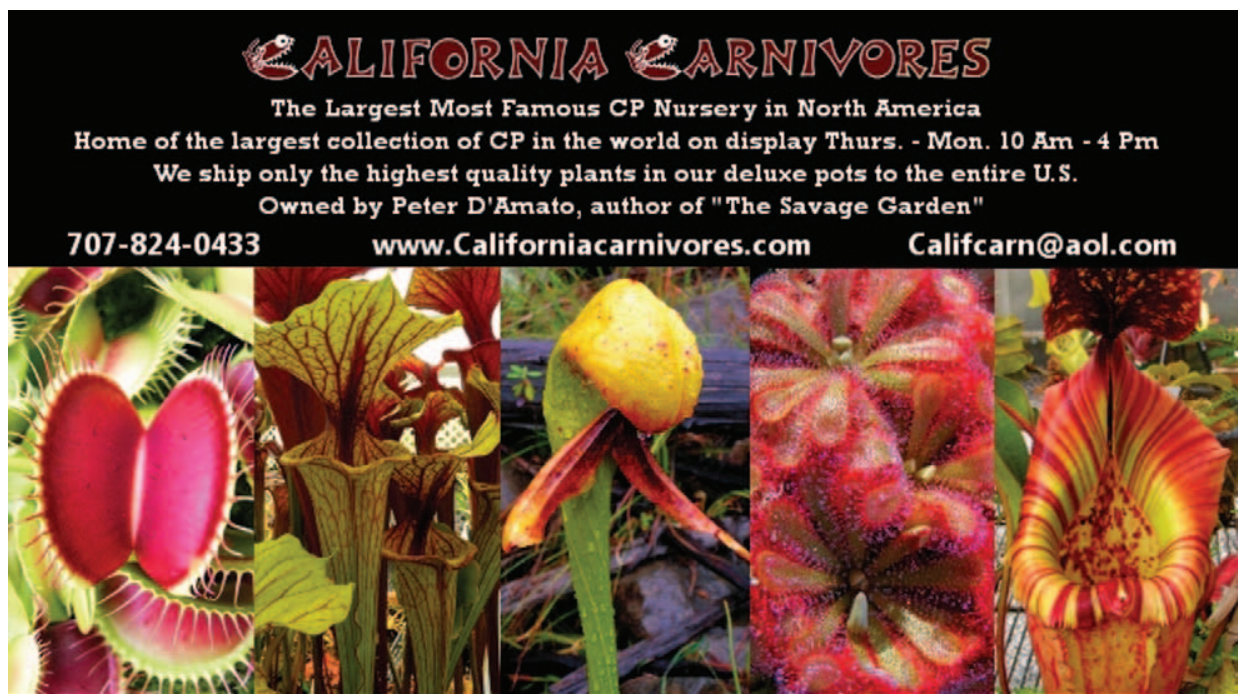

